\title{
Features and Limitations of Mobile Tablet Devices for Viewing Radiological Images
}

\section{Eigenschaften und Einschränkungen mobiler radiologischer Bildwiedergabesysteme}

Author

Affiliation
J. H. Grunert

Radiology, Röntgenpraxis Georgstraße, Hannover, Germany

\author{
Key words \\ - PACS \\ - image manipulation/ \\ reconstruction \\ - QA/QC \\ - technical aspects \\ - mobile viewing \\ - tablet PC
}

received 23.1.2014 accepted $\quad 2.9 .2014$

\section{Bibliography}

DOI http://dx.doi.org/ 10.1055/s-0034-1385293

Published online: 12.11.2014 Fortschr Röntgenstr 2015; 187: 173-179 ๑ Georg Thieme Verlag KG Stuttgart · New York . ISSN 1438-9029

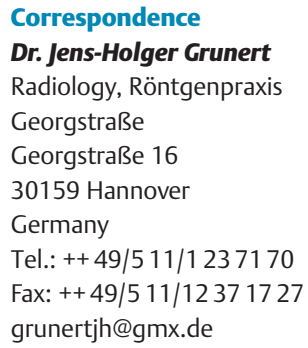

\begin{abstract}
$\nabla$

Purpose: Mobile radiological image display systems are becoming increasingly common, necessitating a comparison of the features of these systems, specifically the operating system employed, connection to stationary PACS, data security and rang of image display and image analysis functions.

Material and methods: In the fall of 2013, a total of 17 PACS suppliers were surveyed regarding the technical features of 18 mobile radiological image display systems using a standardized questionnaire. The study also examined to what extent the technical specifications of the mobile image display systems satisfy the provisions of the Germany Medical Devices Act as well as the provisions of the German X-ray ordinance (RöV).
\end{abstract}

Results: There are clear differences in terms of how the mobile systems connected to the stationary PACS. Web-based solutions allow the mobile image display systems to function independently of their operating systems. The examined systems differed very little in terms of image display and image analysis functions.

Conclusion: Mobile image display systems complement stationary PACS and can be used to view images. The impacts of the new quality assurance guidelines (QS-RL) as well as the upcoming new standard DIN6868-157 on the acceptance testing of mobile image display units for the purpose of image evaluation are discussed.

Key Points:

- The examined mobile image display systems differ very little in terms of image display and analysis functions.

- The use of web-based software allows the mobile image display systems to function independently of their operating systems.
- Individual PACS suppliers enable the mobile systems to connect to the network via their own internet server.

- With zero-footprint technology, no patient data remains on the viewing system once the application is closed.

Citation Format:

- Grunert JH. Eigenschaften und Einschränkungen mobiler radiologischer Bildwiedergabesysteme. Fortschr Röntgenstr 2015; 187: 173-179

\section{Zusammenfassung \\ $\nabla$}

Ziel: Mobile radiologische Bildwiedergabesysteme finden eine zunehmende Verbreitung. Es sollten daher die Eigenschaften einiger dieser Systeme hinsichtlich des verwendeten Betriebssystems, der Anbindung an das stationäre PACS, der Datensicherheit und des Funktionsumfangs der Bilddarstellung und Bildanalyse miteinander verglichen werden.

Material und Methoden: Mithilfe eines standardisierten Fragebogens (Erhebungszeitraum Herbst 2013) wurden die technischen Eigenschaften von 18 mobilen radiologischen Bildwiedergabesystemen bei 17 PACS-Anbietern abgefragt. Des Weiteren wurde untersucht, inwieweit die technischen Spezifikationen der mobilen Bildwiedergabesysteme den Vorgaben des Medizinproduktegesetzes als auch den Vorgaben der Röntgenverordnung (RöV) genügen.

Ergebnisse: Hinsichtlich der Art der Softwareanbindung des mobilen Systems an das stationäre PACS fanden sich deutliche Unterschiede. Webbasierte Systeme ermöglichen eine Unabhängigkeit der mobilen Bildwiedergabesysteme von dem eigenen Betriebssystem. Hinsichtlich der Funktionen der Bilddarstellung und Bildanalyse waren die Unterschiede zwischen den untersuchten Systemen gering. 
Schlussfolgerung: Mobile Bildwiedergabesysteme stellen eine Ergänzung zu stationären PACS dar und sind für die Bildbetrachtung einsetzbar. Die Auswirkungen der neuen Qualitätssicherungs-Richtlinie (QS-RL) sowie der in Kürze erwarteten neuen Norm DIN 6868 - 157 auf die Abnahmeprüfung der mobilen Bildwiedergabegeräte für die Bildbefundung werden diskutiert.

\section{Introduction}

$\nabla$

In 2011 the Food and Drug Administration (FDA-USA, the US food-monitoring and medical product approval agency) granted its first ever approval for the use of mobile image display systems for radiological diagnostics [1]. Since then nearly all PACS (Picture Archiving and Communication System) suppliers have supplemented their stationary radiological imaging systems with mobile units (iPad, tablet, tablet computer, tablet $\mathrm{PC}$, touch-PC), enabling users to call up radiological image information from any location. This also allows the images to be promptly forwarded to the referring physicians or the patients themselves, reducing or eliminating the expenses associated with acquiring film, printing images or creating CDs. Images can also be sent this way to additional physicians for a second opinion or presented at advanced training seminars.

Compared to stationary radiological imaging systems and PACS archives, mobile image display systems have a significantly reduced range of functions. Using manufacturer data and publically accessible information, this article compares the features of mobile image display systems of various PACS providers in terms of operating system, connection to stationary PACS, data security and the range of imaging functions. The article also examines to what extent these systems meet the requirements of the German Medical Devices Act and the German X-ray ordinance.

\section{Material and methods}

$\nabla$

PACS suppliers were asked to provide information on the technical features of their mobile image display systems by completing a standardized questionnaire (data gathered in the fall of 2013). A total of 17 suppliers (18 mobile image display systems) participated in the survey ( $\bullet$ Table 1 ). The questionnaires were supplemented with follow-up telephone calls to individual suppliers and by viewing specifications published on the internet.

The following information was gathered:

- the brand name of the mobile imaging system,

- the operating system used by the mobile imaging system,

- the type of software installed on the mobile imaging system,

- type of connection between the mobile imaging system and the stationary PACS, data security,

- quality of the transmitted images,

- DICOM (Digital Imaging and Communications in Medicine) functions

- image presentation and image analysis functions,

- certification

We also examined to what extent the technical specifications of the mobile image display systems satisfy the provisions of the German Medical Devices Act, Quality Assurance for X-ray Devices, DIN 6868 - 57 as well as the future DIN 6868 - 157.

\section{Results}

$\nabla$

Among the mobile image display systems examined, there are two basic approaches to operating system employed ( $\bullet$ Table 2 ). With the operating-system-specific approach $(6 / 18)$, both the operating system and the hardware are prescribed (in 5/18 cases the iOS operating system from Apple (Apple Inc., Cupertino, CA, USA) with the iPad as hardware). The user loads an application (app) available online from the PACS supplier that contains operating system-

\begin{tabular}{|c|c|}
\hline supplier & $\begin{array}{l}\text { name of mobile image- } \\
\text { viewing system }\end{array}$ \\
\hline aycan Digitalsysteme GmbH, Würzburg, Germany & aycan mobile \\
\hline Agfa HealthCare GmbH, Bonn, Germany & IMPAX ME! \\
\hline Agfa HealthCare GmbH, Bonn, Germany & IMPAXXERO \\
\hline AObit Software Ltd., Sulza (near Jena), Germany & medPool \\
\hline Carestream Health Deutschland GmbH, Stuttgart, Germany & Carestream Vue Motion \\
\hline CHILI GmbH, Dossenheim/Heidelberg, Germany & CHILI/Mobile \\
\hline $\begin{array}{l}\text { Deutsches Krebsforschungszentrum [German Cancer Research Center], } \\
\text { Heidelberg, Germany }\end{array}$ & MITK pocket \\
\hline FUJIFiLM Deutschland GmbH, Düsseldorf, Germany & Synapse mobility \\
\hline GEMED GmbH, Bremen, Germany & GEMED Mobile \\
\hline INFINITT Europe GmbH, Frankfurt / Main, Germany & INFINITT Mobile Viewer \\
\hline medigration GmbH, Erlangen, Germany & PraxisPortal \\
\hline Mint Medical GmbH, Dossenheim, Germany & Mobile MIM \\
\hline Oehm und Rehbein GmbH, Rostock, Germany & dicomPACS MobileView \\
\hline Philips GmbH, Unternehmensbereich Healthcare, Hamburg, Germany & IntelliSpace PACS Anywhere \\
\hline Pixmeo SARL & OsiriX HD \\
\hline Sectra Medical Systems GmbH, Cologne, Germany & Sectra LiteView \\
\hline Siemens AG, Siemens Deutschland, Healthcare Sector, Erlangen, Germany & syngo.via WebViewer \\
\hline VISUS Technology Transfer GmbH, Bochum, Germany & JiveX Mobile \\
\hline
\end{tabular}

Table 1 Mobile image-viewing systems examined in the present study $(n=18)$. 
Table 2 Operating systems used by the mobile image display systems.

\begin{tabular}{|l|l|}
\hline operating system & $\begin{array}{l}\text { number of mobile } \\
\text { image display systems } \\
\mathbf{n = 1 8}\end{array}$ \\
\hline $\begin{array}{l}\text { operating system-specific with own } \\
\text { application (App) } \\
\text { iOS (Apple) }\end{array}$ & 5 \\
\hline $\begin{array}{l}\text { operating system-specific with own } \\
\text { application (App) } \\
\text { iOS (Apple) and Android (Google) }\end{array}$ & 1 \\
\hline $\begin{array}{l}\text { not operating system-specific, web-based } \\
\text { without (optional) app } \\
\text { with web browser }\end{array}$ & \\
\hline $\begin{array}{l}\text { not operating system-specific, web-based } \\
\text { with (optional) app } \\
\text { iOS (Apple) }\end{array}$ & 8 \\
\hline $\begin{array}{l}\text { not operating system-specific, web-based } \\
\text { with (optional) app } \\
\text { iOS (Apple) and Android (Google) }\end{array}$ & 2 \\
\hline
\end{tabular}

Table 3 Data transmission between from PACS to mobile image display system.

\begin{tabular}{|l|l|}
\hline data Transfer & $\begin{array}{l}\text { number of mobile } \\
\text { image display systems } \\
\mathbf{n = 1 8}\end{array}$ \\
\hline $\begin{array}{l}\text { wireless Local Area Network } \\
\text { (W-LAN) }\end{array}$ & 18 \\
\hline wireless phone network & 18 \\
\hline
\end{tabular}

Table 4 Connection between mobile image display system and PACS supplier's external server.

\begin{tabular}{|ll|}
\hline network connection & $\begin{array}{l}\text { number of mobile } \\
\text { image display systems } \\
\mathbf{n = 1 8}\end{array}$ \\
\hline PACS provider's internet server (cloud) & 7 \\
\hline
\end{tabular}

specific radiological image presentation functions. The second approach $(12 / 18)$ is to use the internet browser independently of operating system to display the images (webbased). In addition to offering web-based display in the internet browser, 4 of these 12 systems offer apps for the iOS (Apple) (2/18) or the Android operating system from Google (Google Inc., Mountain View, CA, USA) (2/18).

Data can be transmitted via Wireless Local Area Network (W-LAN) (18/18) or and/or mobile phone network (18/18) according to hardware used ( $\bullet$ Table 3 ).

Generally, network connection is established directly with the PACS server at the medical office or hospital. In 7 of 18 systems there is the option of connecting to the PACS supplier's external server in which imaging data previously received from the medical office or hospital has been archived (external cloud solution) (๑ Table 4).

Data security is ensured through data encryption in the majority of systems (16/18). Of 18 systems, only 5 anonymize patient images ( $\odot$ Table 5). Zero-footprint technology, which means that absolutely no traces of data are left behind once the application is closed, is employed in 11 of 18 systems.
Table 5 Data security for both data transmission as well as data storage on the mobile image display system.

\begin{tabular}{|l|l|}
\hline data security & $\begin{array}{l}\text { number of mobile } \\
\text { image display systems } \\
\mathbf{n = 1 8}\end{array}$ \\
\hline data encryption & 16 \\
\hline anonymization & 5 \\
\hline zero-footprint technology & 11 \\
\hline
\end{tabular}

Table 6 Image compression on the mobile image display systems.

\begin{tabular}{|l|l|}
\hline image compression & $\begin{array}{l}\text { number of mobile } \\
\text { image display systems } \\
\mathbf{n = 1 8}\end{array}$ \\
\hline no image data compression & 13 \\
\hline $\begin{array}{l}\text { image data compression used (e. g. lossy } \\
\text { JPEG format) }\end{array}$ & 13 \\
\hline both image formats & 8 \\
\hline
\end{tabular}

Table 7 DICOM (Digital Imaging and Communications in Medicine) functions available on the mobile image display systems.

\begin{tabular}{|l|l|}
\hline DICOM functions & $\begin{array}{l}\text { number of mobile } \\
\text { image display systems } \\
\mathbf{n = 1 8}\end{array}$ \\
\hline basic & 17 \\
\hline patient list & 12 \\
\hline query/retrieve & \\
\hline advanced & 6 \\
\hline work list management & 5 \\
\hline hanging protocol & \\
\hline
\end{tabular}

Images are transmitted without image data compression in 13 of 18 cases. In 13 of 18 mobile image viewing systems, compressed image formats are transmitted in lossy JPEG format. The user can select between these two formats in 8 of 18 systems ( $\bullet$ Table 6 ).

The DICOM functions of most mobile image display systems are limited to simple functions such as patient list (17/18) or DICOM query/retrieve (12/18). Additional DICOM functions such as work list management or hanging protocols are available on only 6 and 5 of 18 systems, respectively (० Table 7).

The systems differ insignificantly in terms of basic image viewing and analysis functions such as navigating (18/18), moving $(17 / 18)$, enlarging $(18 / 18)$, windowing $(17 / 18)$ or turning $(15 / 18)$ the image. Offering distance (13/18) and angle measurement (6/18) as well as ROI functions is not mandatory.

A total of 5 of 18 systems feature expanded functions such as multiplanar reconstruction (MPR). Only two systems offer a special program (image fusion (PET)) on the mobile unit ( $\odot$ Table 8).

CE certification with conformity assessment procedure in accordance with the German Medical Products Act is available in 14 of 18 systems. Of the remaining 4 systems, 3 plan to have or have applied for CE certification ( $\bullet$ Table 9 ). 
Table 8 Image presentation and image analysis functions of the mobile image display systems.

\begin{tabular}{|l|l|}
\hline $\begin{array}{l}\text { image presentation and image analysis } \\
\text { functions }\end{array}$ & $\begin{array}{l}\text { number of mobile } \\
\text { image display systems } \\
\mathbf{n = 1 8}\end{array}$ \\
\hline $\begin{array}{l}\text { basic functions } \\
\text { navigation }\end{array}$ & 18 \\
\hline move & 17 \\
\hline enlarge & 18 \\
\hline window functions & 17 \\
\hline rotate & 15 \\
\hline distance measurement & 13 \\
\hline angle measurement & 6 \\
\hline region of interest (ROI) functions & 10 \\
\hline 3D functions & 1 \\
\hline mean computation & 5 \\
\hline multiplanar reconstruction (MPR) & 3 \\
\hline maximum intensity projection (MIP) & 2 \\
\hline shaded surface display (SSD) & 2 \\
\hline special programs & \\
\hline image fusion (positron emission tomo- \\
graphy, PET)
\end{tabular}

Table 9 Certifications held by the mobile image display systems.

\begin{tabular}{|l|l|}
\hline certification & $\begin{array}{l}\text { number of mobile } \\
\text { image display systems } \\
\mathbf{n = 1 8}\end{array}$ \\
\hline CE certification with conformity assessment procedure \\
\hline existing & 14 \\
\hline not existing (planned/requested) & $4(3)$ \\
\hline FDA (US Food and Drug Administration) & 4 \\
\hline FDA (Canadian Food and Drug & 1 \\
\hline Administration) & \\
\hline
\end{tabular}

\section{Discussion}

$\nabla$

The use of mobile image display systems with the aid of a personal digital assistant (PDA) available at that time in conjunction with the DICOM standard was reported as early as 2003 [2]. In 2011 the Food and Drug Administration (FDAUSA, the US food monitoring and pharmaceutical approval authority) granted initial approval to Software Mobile MIM (MIM Software Inc., Cleveland, OH, USA) for using an iPad for radiological diagnostics [1.3].

Since then, multiple studies have been published that have examined the evaluation quality of mobile image display systems compared to the monitors on the stationary workstations. These studies cover conventional chest radiographs [4], cerebral computed tomography scans (CT) following recent cerebral infarction [5, 6], CT scans of intracerebral hemorrhaging $[7,8]$, CT scans following cervical spinal cord injury [9], magnetic resonance imaging (MRT) following spinal cord injury [10], CT scans in cases of appendicitis [11] and computed tomography angiograms (CTA) of the pulmonary arteries for diagnosing pulmonary embolisms $[5,12]$. Nearly all studies found no significant differences in terms of diagnostic quality among the systems being compared. One study detected significantly worse results for the iPad when it came to diagnosing cerebral infarctions [6].

With mobile image display systems becoming increasingly common in routine clinical medicine, it was expedient to examine the features of several of these systems in terms of operating system, link to stationary PACS, data security and range of functions.

There are two different approaches for establishing software connection between the mobile viewing system and the stationary PACS. The first approach is specific to operating system. In this case, the mobile display system user obtains a small manufacturer-specific radiological image processing program (app) from a "store" (App Store (iOS) or Google Play Store (Android)) and installs it. Among the systems examined, this solution is used primarily for the iOS system. The other approach is through web-based solutions which are not specific to any operating system and use the mobile web browser for displaying radiological images. This approach thus also allows the connection of external PCs and laptops.

Data is transmitted from the PACS (server) to mobile viewing system (mobile client) via a local wireless network (WLAN) or a mobile phone link. $\odot$ Table 10 presents the transmission times for an MRI examination with 200 images (approx. 100 megabytes (MB) corresponding to 838860.8 kbit) broken down by transmission method and data compression rate, showing that older wireless communication standards such as General Packet Radio Service (GPRS) involve transmission times exceeding two hours. Only newer standards (LTE, Long Term Evolution), which are not yet universally available in Germany, facilitate faster access [13].

It must also be taken into consideration that mobile phone network providers currently impose limits on data volumes transmitted in fast mode, which, in less favorable cases, are exceeded with simply the transmission of 10 MRI examinations per month. The mobile phone network provider's considerably slower transmission rate (for example $64 \mathrm{kbit} / \mathrm{s}$ ) taking effect upon maximum data volume being reached is not suitable for the rapid transmission of extensive examinations.

Pursuant to $\S 28$ Paragraph 5 Clause 2 of the German X-ray ordinance (RöV) compression of X-ray image files is permitted as long as it does not compromise the diagnostic value of the images (14). A consensus conference was held that specified permissible compression factors for the different examination modalities as well as for the archiving of radiological image data and the teleradiological data transmission to ensure that the image quality required by the German X-ray ordinance is maintained ( $\odot$ Table 10) [15]. The results of this consensus conference influenced the recommendations of the Radiation Protection Commission regarding data compression in X-ray images $[16,17]$.

The individual suppliers also offer two different methods for connecting to the PACS. With the first method, the mobile image viewing system logs directly into the local network (PACS in hospital or medical office) as a client. With the second method, the stationary hospital/medical office PACS sends the image data to a PACS provider server, where it is then archived (external internet server, external cloud) and can be called up by mobile devices via the internet. 


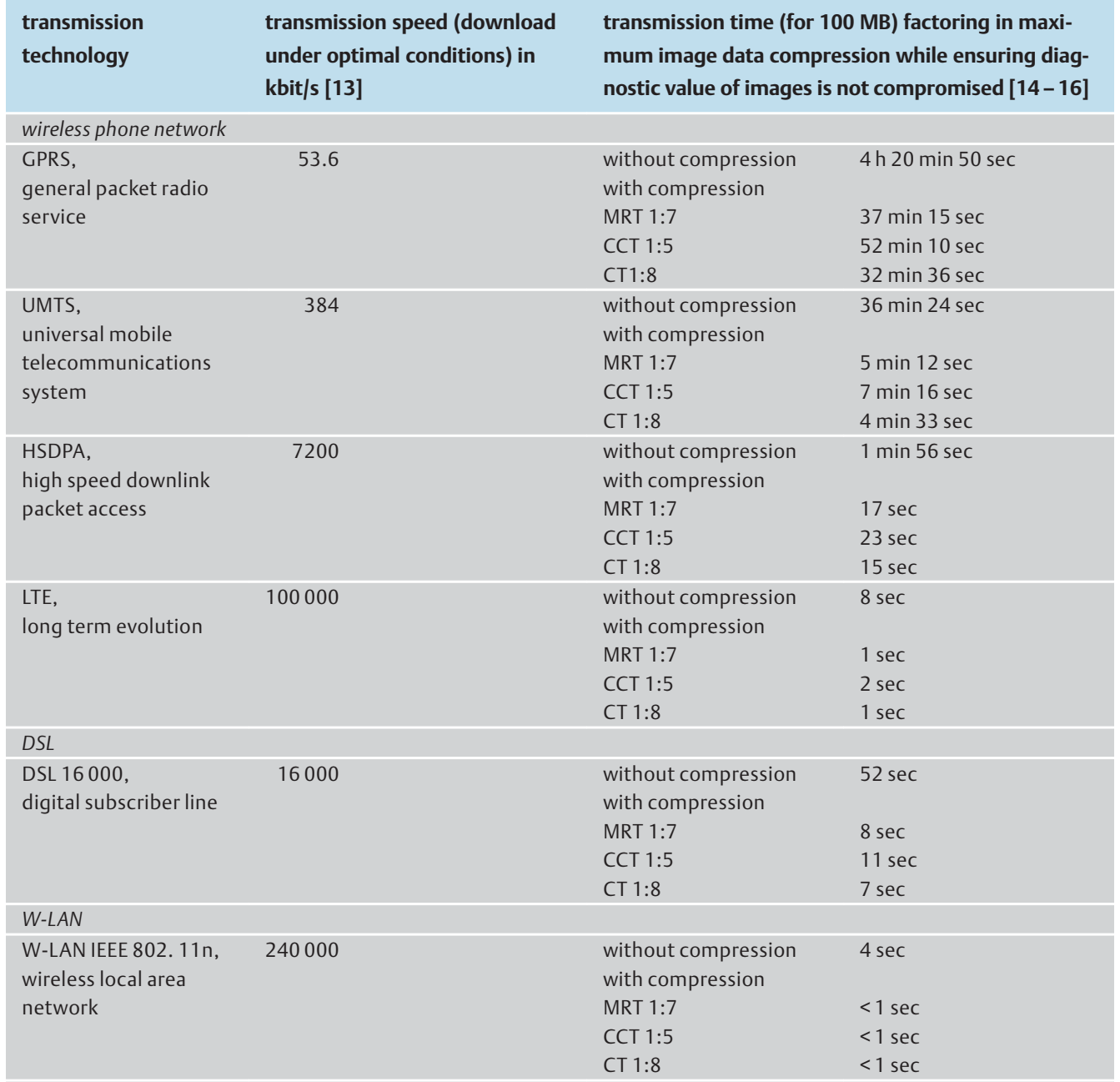

Table 10 Downlink transmission time for an MRI or CT examination (200 DICOM images, 100 megabytes, $838860.8 \mathrm{kbit})$.
Data security is ensured through data encryption in the majority of systems. Only a few systems anonymize patient images. Data security is essential not only for data transmission, but also for protecting patient data on the mobile system itself is essential. This is especially important when a device is lost. With zero-footprint technology, patient data and images are ideally saved only to the RAM of the mobile device and are no longer available on the image viewing system once the mobile image viewing application has been closed. As a "slim client" the mobile image viewing system receives the data from the server similar to the "streaming" of a movie. Another aspect of this technology is the shifting of complex computing activities such as $3 \mathrm{D}$ computations to the server, thus taking workload off the mobile device.

With regard to the image display and analysis functions, the systems differ very little in terms of standard functions, which are limited to the basics. Three-dimensional reconstructions and special analytical programs are generally not available on mobile systems.

Pursuant to the German Medical Products Act, products of medical nature must undergo a conformity assessment procedure documenting that they meet the protection and safety goals of the Medical Device Directive [3, 18]. Mobile image display systems and associated software used for medical purposes fall under this category of products. Only after the manufacturer has documented the harmlessness of its product in accordance with the German Medical Products Act and has issued a "Declaration of Conformity" may it affix the CE mark. Products falling under a higher risk class are subject to review by an external body ("Notified Body"). PACS software (e.g. for the archiving and evaluation of image data) is generally marketed as a class IIa medical product throughout the entire European Union. A product is legally required to bear the $\mathrm{CE}$ mark before it can be used in the medical field.

However, a CE mark does not mean that the mobile image viewing system is approved for the evaluation of conventional X-ray images or CT scans. The act of "evaluation" is to answer diagnostic inquiries and possibly provide the basis for a medical decision, while the act of "viewing" is strictly for the purpose of medical information, demonstration and monitoring. Image-viewing systems used solely for viewing purposes are not subject to quality assurance pursuant to $\S 16$ of the German X-ray ordinance (RöV). When a device is used solely for viewing, the presentation of diagnosis-relevant image content may be limited by lower spatial and contrast resolution or lower light density. When it comes to "viewing" X-ray images there are merely quality recommendations for image viewing systems, which, unlike the requirements for "evaluation", are not binding.

The acceptance test for an image viewing system to be used for evaluating X-rays or CT scans (MRI examinations are not affected) is subject to the most recent version of the "Guide- 


\begin{tabular}{|c|c|c|c|c|}
\hline bodily region/methods & $\begin{array}{l}\text { application } \\
\text { category }\end{array}$ & $\begin{array}{l}\text { max. light density } \\
\left(\mathrm{cd} / \mathrm{m}^{2}\right)\end{array}$ & matrix & $\begin{array}{l}\text { diagonal LCD } \\
\text { (inches) }\end{array}$ \\
\hline mammography & A & $\begin{array}{l}>250 \\
(>250)\end{array}$ & $\begin{array}{l}>=2000 x>=2500 \\
(>=2048 x>=2048)\end{array}$ & $>=19$ \\
\hline thorax & A & $\begin{array}{l}>200 \\
(>250)\end{array}$ & $\begin{array}{l}>=2000 x>=2000 \\
(>=1600 x>=1200)\end{array}$ & $>=19$ \\
\hline $\begin{array}{l}\text { extremities, cranial } \\
\text { overview }\end{array}$ & A & $\begin{array}{l}>200 \\
(>250)\end{array}$ & $\begin{array}{l}>=1000 x>=1000 \\
(>=1600 x>=1200)\end{array}$ & $>=17$ \\
\hline $\begin{array}{l}\text { extremities, cranial struc- } \\
\text { tures }\end{array}$ & A & $\begin{array}{l}>200 \\
(>250)\end{array}$ & $\begin{array}{l}>=2000 x>=2000 \\
(>=1600 x>=1200)\end{array}$ & $>=17$ \\
\hline $\begin{array}{l}\text { cervical, thoracic, lumbar } \\
\text { spinal columns and pelvis }\end{array}$ & A & $\begin{array}{l}>200 \\
(>250)\end{array}$ & $\begin{array}{l}>=1000 x>=1000 \\
(>=1600 x>=1200)\end{array}$ & $>=17$ \\
\hline abdomen, urinary tract & A & $\begin{array}{l}>200 \\
(>250)\end{array}$ & $\begin{array}{l}>=1000 x>=1000 \\
(>=1600 x>=1200)\end{array}$ & $>=17$ \\
\hline CT & B & $\begin{array}{l}>120 \\
(>150)\end{array}$ & $\begin{array}{l}>=1000 x>=1000 \\
(>=1024 x>=1024)\end{array}$ & $>=15$ \\
\hline \multicolumn{5}{|c|}{ mobile image-viewing systems (sample devices) } \\
\hline $\begin{array}{l}\text { iOS } \\
(\text { e. g. iPad 4) [23] }\end{array}$ & - & 335 & $2048 \times 1536$ & 9.7 \\
\hline $\begin{array}{l}\text { Android } \\
\text { (e. g. Google Nexus 10) [24] }\end{array}$ & - & 374 & $2560 \times 1600$ & 10.1 \\
\hline
\end{tabular}

Table 11 Minimum requirements for image display unit monitors to be used for evaluation purposes according to the quality assurance guideline (QS-RL, Table 8.1 [19]) as well as according to the drafted version of DIN 6868 157 (values in parentheses) [21] compared to the displays of commercially available mobile computer systems. lines for Performing Quality Assurance Testing of Radiological Devices for Examining or Treating Humans (QS-RL)" dated June 23, 2014 [19]. With regard to acceptance testing as well as regular consistency testing of image viewing systems, this directive cites both the applicable DIN 6868 - 57 [20] as well as the soon to be published DIN 6868 - 157 [21, $22]$. The still valid DIN 6868 - 57 does not approve the use of commercially available mobile systems with a 10-inch diagonal display, since the "evaluation" of CT scans requires a minimum diagonal screen size of 15 inches ( $\bullet$ Table 11).

The new DIN 6868-157, which will soon replace the old DIN standard 6868-57, omits the minimum diagonal screen size requirement and instead specifies minimum pixel size in both dimensions at $140 \mu \mathrm{m}$ [21, 22]. Taking the matrix requirements of DIN6868-157 for evaluating CT scans (1024x1024) and multiplying the values by the minimum pixel size of $140 \mu \mathrm{m}$ yields a minimum display size of $14.3 \mathrm{~cm} \times 14.3 \mathrm{~cm}$. The "Retina Display" of the iPad ( $3 \mathrm{rd}$ and 4 th generation) has a pixel size in both dimensions of $96.2 \mu \mathrm{m}$ (264 pixels per inch ) [23]. Software solutions are being discussed for these high-resolution displays that use interpolation to show the appropriate TG 18 test image in the prescribed minimum resolution (e.g. CT $1024 \times 1024$ ) with a presented pixel size of $140 \mu \mathrm{m}$ edge length so that the displayed pixels can be clearly differentiated and thus meet the requirements.

Additional new quality requirements of DIN 6868-157 which the mobile imaging devices must meet if they are to be used for evaluation are the definition of space classes while factoring in the influence of ambient lighting on the evaluation monitor, compliance with light density characteristic curve according to the DICOM-Grayscale-StandardDisplay-Function (GSDF), the homogeneity of light density on the monitor as well as the degree of pixel errors. Documented experience with acceptance testing of mobile image viewing systems according to the future DIN 6868 157 is not currently available.

\section{Clinical relevance of the study:}

- The evaluation of X-rays and CT scans on mobile image display systems is currently not permitted. While the upcoming new DIN 6868 - 157 eliminates the minimal diagonal screen size, it defines a number of new technical quality guidelines that must be satisfied for a device to pass acceptance testing.

- The approval of mobile image display systems for radiological evaluation by foreign authorities (e.g., FDA approval) does not replace the approval of systems under German law pursuant to the German X-ray ordinance (RöV).

- With regard to the connection of tablet PCs to the stationary PACS, it must be noted that several suppliers' stationary PACS do not support tablet systems using the Android operating system. The iOS operating system in contrast is supported by all stationary PACS regardless of supplier.

- The mobile network transmission of MRI and CT scans to the mobile image display system requires fast mobile network standards such as HSDPA (High Speed Downlink Packet Access) or LTE (Long Term Evolution).

\section{Acknowledgements}

We would like to extend our special thanks to Dr. Wolfgang Pethke, Hannover

Medical Association of Lower Saxony / Bremen [Ärztliche Stelle Niedersachsen / Bremen] as well as

Dr. Bernd Seidel and Mr. Matthias Wedel, Erlangen

Radiology Standards Committee [Normenausschuss Radiologie ] (NAR) for their valuable contributions. 


\section{Literatur}

1 FDA. FDA clears first diagnostic radiology application for mobile devices. Silver Spring, Maryland, USA: 2011, Erreichbar unter: http:// www.fda.gov/NewsEvents/Newsroom/PressAnnouncements/2011/ ucm242295.htm

2 Andrade $R$, Wangenheim AV, Bortoluzzi MK et al. Wireless and PDA: a novel strategy to access DICOM-compliant medical data on mobile devices. Int J Med Inf 2003; 71: 157-163

3 Albracht UV, von Falk CH, Pramann O. Einsatz in der Grauzone. Dtsch Ärztebl 2013; 14: 652 -654

4 Abboud S, Weiss F, Siegel E et al. TB or Not TB: interreader and intrareader variability in screening diagnosis on an iPad versus a traditional display. JACR 2013; 10: $42-44$

5 Tewes S, Rodt T, Marquardt $S$ et al. Evaluation eines Tablet-Computers mit hochauflösendem Display zur Befundung von Notfall-CT-Untersuchungen. Fortschr Röntgenstr 2013; 185: 1063 -1069

6 Yoshimura K, Nihashi T, Ikeda M et al. Comparison of liquid crystal display monitors calibrated with gray-scale standard display function and with gamma 2.2 and iPad: observer performance in detection of cerebral infarction on brain CT. Am J Roentgenol 2013; 200: 1304-1309

7 Mc Laughlin P, Neill SO, Fanning $N$ et al. Emergency CT brain: preliminary interpretation with a tablet device: image quality and diagnostic performance of the Apple iPad. Emerg Radiol 2012; 19: 127-133

8 Park JB, Choi HJ, Lee JH et al. An assessment of the iPad 2 as a CT teleradiology tool using brain CT with subtle intracranial hemorrhage under conventional illumination. J Digit Imaging 2013; 26: 683-690

9 Modi J, Sharma P, Earl A et al. iPhone-based teleradiology for the diagnosis of acute cervico-dorsal spine trauma. Can J Neurol Sci 2010; 37: $849-854$

10 McNulty JP, Ryan JT, Evanoff MG et al. Flexible image evaluation: iPad versus secondary-class monitors for review of MR spinal emergency cases, a comparative study. Acad Radiol 2012; 19: 1023-1028

11 Choudhri AF, Carr TM, Ho C et al. Handheld device review of abdominal CT for the evaluation of acute appendicitis. J Digit Imaging 2012; 25 : $492-496$

12 Johnson PT, Zimmerman SL, Heath $D$ et al. The iPad as a mobile device for CT display and interpretation: diagnostic accuracy for identification of pulmonary embolism. Emerg Radiol 2012; 19: 323 - 327

13 Dühmke R. HSDPA.org. Ratgeber für HSDPA \& Mobiles Internet; 2010 , Erreichbar unter: http://www.hsdpa.org/hsdpa-vergleich-mit-anderen-technologien.html
14 Verordnung über den Schutz vor Schäden durch Röntgenstrahlen (Röntgenverordnung) in der Fassung der Bekanntmachung vom 30. April 2003 (BGBl. I S. 604), die durch Artikel 2 der Verordnung vom 4. Oktober 2011 (BGBl. I S. 2000) geändert worden ist

15 Loose R, Braunschweig R, Kotter E et al. Kompression digitaler Bilddaten in der Radiologie - Ergebnisse einer Konsensuskonferenz. Fortschr Röntgenstr 2009; 181: 32 - 37

16 Strahlenschutzkommission (SSK). Datenkompression bei Röntgenbildern. Empfehlung der Strahlenschutzkommission. Erreichbar unter: www.ssk.de

17 Normenausschuss Radiologie (NAR). DIN 6868-159: Sicherung der Bildqualität in röntgendiagnostischen Betrieben - Teil 159: Abnahmeund Konstanzprüfung in der Teleradiologie nach RöV

18 Pramann O, Gärtner A, Albrecht UV. Mobile Helfer am Krankenbett. Dtsch Ärztebl 2012; 109: 1025-1026

19 Bundesministerium für Umwelt, Naturschutz, Bau und Reaktorsicherheit. Richtlinie zur Durchführung der Qualitätssicherung bei Röntgeneinrichtungen zur Untersuchung oder Behandlung von Menschen nach den $\S \S 16$ und 17 der Röntgenverordnung - Qualitätssicherungs-Richtlinie (QS-RL) vom 23. Juni 2014. Gemeinsames Ministerialblatt 2014

20 Normenausschuss Radiologie (NAR). DIN V 6868-57: Sicherung der Bildqualität in röntgendiagnostischen Betrieben - Teil 57: Abnahmeprüfung an Bildwiedergabegeräten in ihrer Umgebung

21 Normenausschuss Radiologie (NAR). DIN 6868-157: Sicherung der Bildqualität in röntgendiagnostischen Betrieben - Teil 157: Abnahmeund Konstanzprüfung nach RöV an Bildwiedergabegeräten (Entwurf vom November 2013)

22 Normenausschuss Radiologie (NAR). Protokoll der Beratung der Stellungnahmen nach DIN 820 Teil 4 zum Norm-Entwurf DIN 6868-157: 2013-11 (Zweiter Entwurf) am 6. Februar 2014 in Erlangen. Sicherung der Bildqualität in röntgendiagnostischen Betrieben - Teil 157: Abnahme- und Konstanzprüfung nach RöV an Bildwiedergabesystemen in ihrer Umgebung

23 Barczok A, Wölbert C. iPad vs. Android. Das neue iPad im Vergleich mit dem iPad 2 und den besten Android-Tablets. 2012. Erreichbar unter: http://www.heise.de/ct/artikel/Das-neue-iPad-im-Vergleich-mitdem-iPad-2-und-den-besten-Android-Tablets-1901934.html

24 Rau T. Tablet-PC. Google Nexus 10 im Test; 2013, Erreichbar unter: http://www.pcwelt.de/produkte/Google-Nexus_10-Tablet-PC-Test$7534750 . \mathrm{html}$ 